\title{
MODELING AND SIMULATION OF A BATTERY CHARGING CIRCUIT FOR ELECTRIC VEHICLES USING Z-SOURCE CONVERTER
}

\author{
Aayush Bafna, Arjun Murali, Chetan Chandrakant Kamath, K Jatin Bhat \\ Under Graduate Student, \\ Department of Electrical and Electronics, \\ B.M.S College of Engineering, \\ Bengaluru, India
}

Divya $S$

Assistant Professor,

Department of Electrical and Electronics Engineering,

B.M.S College of Engineering,

Bengaluru, India

\begin{abstract}
Z$ source is a versatile switched mode power converter that can handle conversions between alternating and direct current with desired, controlled values. It is an improvement on traditional switched mode converters which gives a good protection against in-rush and ripple currents. In a world with increasing demand for more efficient and fail proof power electronics devices and rise in popularity of electric vehicles, $Z$ source converter provides a good alternative to charge vehicle batteries quickly and efficiently. This paper presents a method of implementing Z-Source Converter (ZSC) to charge the vehicle battery from the grid using AC-DC power conversion with constant current (CC) and constant voltage (CV) charging modes. Theoretical design for charging modes between threshold values is done and the circuit with waveforms is simulated and verified.
\end{abstract}

Keywords-Z-Source converter, CC-CV charging, Electric Vehicles(EV), MATLAB Simulink.

\section{INTRODUCTION}

Eco friendly automotive has been the constant topic of research for quite some time and electric vehicles has been in the fore front of it. Electric vehicles [EV] use electric motors for propulsion and run on electric power. Recent advancements have provided a break-through in the field of EV which has led the trend of increasing usage of it. Electric vehicles reduce the dependence on oil/petrol for transportation. This necessitates efficient and quick charging of EV's battery.

There are two types of chargers for EVs: On-board charger and Off-board charger. On-board chargers take AC as its input. The power conversion takes place inside the vehicle where the circuitry is placed. In Off-board chargers, the power conversion is done outside the vehicle and the converted power is directly supplied to the battery. Charging circuit has 3 key functions getting charge into battery, optimizing charging rate and terminating charging at full battery. Optimization can be obtained by multiple charging methods based on type of battery and input power. The basic charging methods are -

1. Constant Voltage - In this charging methodology, a constant supply voltage is maintained across battery terminals, providing steady charging

2. Constant Current - In this charging methodology, supply voltage is varied to maintain constant current for faster charging

This work aims to reduce the converter losses and also to reduce the component cost of the converter. To implement this, a Z-source topology-based converter is used. This network can be used in AC-AC, AC-DC, DC-DC and DC-AC power conversion operations. Traditional $\mathrm{Z}$ source converter has the standard $\mathrm{Z}$ network used with an interface diode between input and $\mathrm{Z}$ network and a controlled switching device between $\mathrm{Z}$ network and output filter/load. Position of diode and switching device can be changed to obtain voltage source and current source.[3]

For this design, Constant Current (CC) and Constant Voltage (CV) charging mode is used to charge the battery. To maintain constant output values during various phases, closed loop feedback control is used.

\section{Z-SOURCE CONVERTER}

\section{A. Topology}

The converter shown in Fig. 1 consists of a diode $D_{l}$, two identical inductors and capacitors denoted by $L$ and $C$ respectively and are connected in the manner as shown to obtain the Z-network. An active switch $S$ (MOSFET or IGBT) is used to implement the circuit states and a second order low pass filter is used which is formed by inductor $L f$ and capacitor $C f$. Equivalent DC voltage source $V i$ is taken as the primary source. A resistive load $R l$ is used for analysis. 


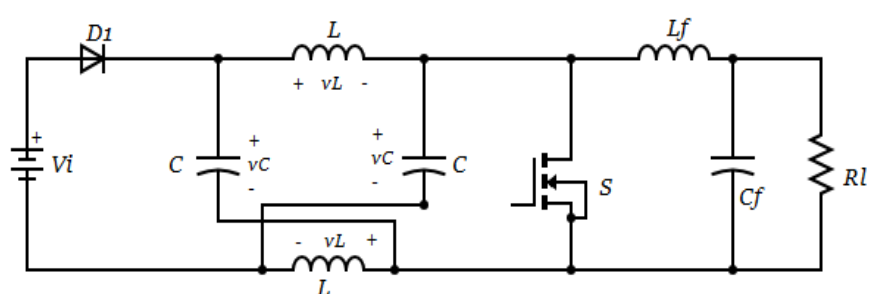

Fig. 1. Z-Source Converter (ZSC)

Assumptions made for the analysis -

1. All passive devices are linear, time-invariant and frequency independent.

2. Switches (MOSFET and diode) are ideal.

3. Natural time constant of converter is much greater than the switching time period.

4. Due to symmetry of Z-network,

$$
\begin{aligned}
& L_{1}=L_{2}=L \\
& C_{1}=C_{2}=C
\end{aligned}
$$

\section{$B$. Steady State Analysis}

For analysis, two separate time intervals are considered. For time interval $0<\mathrm{t}<\mathrm{dT}$, consider the circuit shown in Fig.2

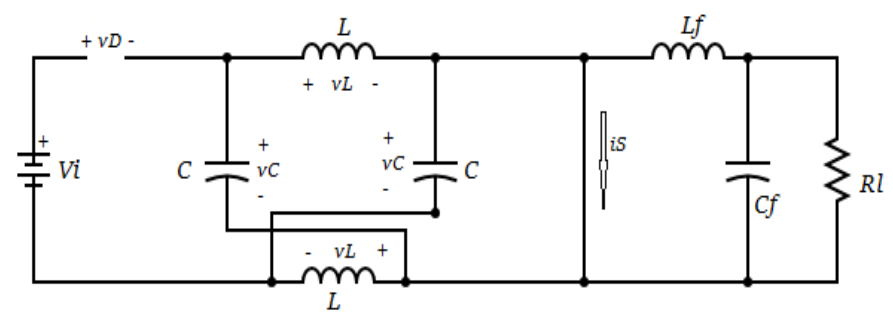

Fig. 2. Interval $0<\mathrm{t}<\mathrm{dT}$

Here, Voltage across diode is $V i-2 v C$, leading to diode being reverse biased. This isolates energy source $V i$ from rest of the circuit. Voltage across inductor $L$ is

$$
v L=2 v C-v C=v C
$$

For time interval $\mathrm{dT}<\mathrm{t}<\mathrm{T}$, consider the circuit shown in Fig.3

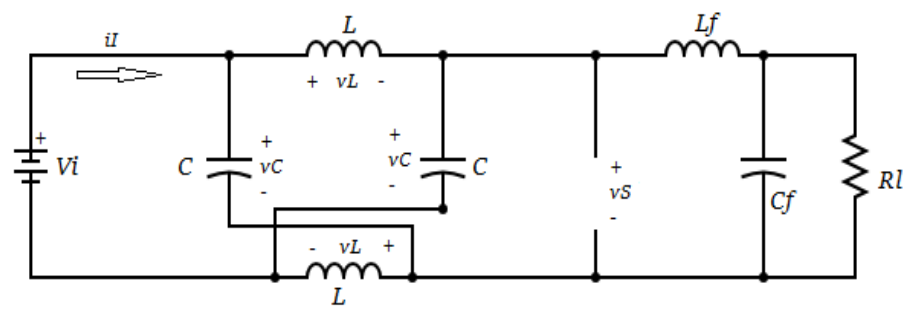

Fig. 3. Interval $d \mathrm{~T}<\mathrm{t}<\mathrm{T}$
Here, diode $D_{l}$ is forward biased and $S$ is $O F F$. In this state, the Z-network is an interface between source and load. The voltage across inductor $L$ is given by

$$
v L=V i-v C
$$

Using volt-second balance,

$$
\int_{0}^{d T} v L(t) d t+\int_{d T}^{T} v L(t) d t=0
$$

$$
\mathrm{V}_{\mathrm{C}} * \mathrm{dT}+\left(\mathrm{Vi}-\mathrm{V}_{\mathrm{C}}\right) *(1-\mathrm{d}) * \mathrm{~T}=0
$$

$$
\frac{\mathrm{Vc}}{\mathrm{Vi}}=\frac{1-d}{1-2 d}
$$

Using KVL in the circuit

$$
V_{C}-v L-v L f-V_{0}=0
$$

Since average voltage across inductor is zero, equation 6 can be written as,

$$
\begin{gathered}
V_{C}=V_{0} \\
\frac{V_{0}}{\operatorname{Vin}}=\frac{1-d}{1-2 d}
\end{gathered}
$$

Now,

$$
\begin{gathered}
\Delta i_{L}=i_{L}(\mathrm{dT})-i_{L}(0) \\
\Delta i_{L}=\frac{V_{C}}{\mathrm{~L}} \mathrm{dT} \\
\partial i_{L}=\frac{\Delta i_{L}}{I_{a v g}}
\end{gathered}
$$

$$
\text { Since } \begin{aligned}
V_{\mathrm{c}} & =V_{0} \\
I_{\text {avg }} & =I_{0}
\end{aligned}
$$

Therefore

$$
\begin{gathered}
\partial i_{L}=\frac{V_{0}}{\mathrm{~L} * \mathrm{I}_{0}} \mathrm{dT} \\
\partial i_{L}=\frac{\mathrm{R}}{\mathrm{L}} \mathrm{dT}
\end{gathered}
$$

Current through capacitor,

$$
i_{C}=i_{L}-I_{0}
$$




$$
\begin{gathered}
\Delta V_{C}=\left(\frac{1}{2} * \frac{\mathrm{T}}{2} * \frac{\Delta i_{L}}{2}\right) * \frac{1}{\mathrm{C}} \\
\Delta V_{C}=\frac{\mathrm{T}}{8 \mathrm{C}} * \Delta i_{L} \\
\Delta V_{C}=\frac{\mathrm{T}\left(V_{0}\right) \mathrm{dT}}{8 \mathrm{LC}} \\
\Delta V_{C}=\frac{\left(V_{0}\right) \mathrm{dT}^{2}}{8 \mathrm{LC}} \\
\partial V_{C}=\frac{\mathrm{dT}^{2}}{8 \mathrm{LC}}
\end{gathered}
$$

\section{Advantages}

1. The source can be either a voltage source or a current source. The DC source of a ZSC can either be a battery, a diode rectifier or a thyristor converter, a fuel cell stack or a combination of these.

2. The main circuit of a ZSC can either be the traditional Voltage Source Converter (VSC) or the traditional Current Source Converter (CSC).

3. Works as a buck-boost inverter.

4. The load of a ZSC can either be inductive or capacitive or another Z-Source network.

Common problems with both $\mathrm{V}$ and I source converters are:

- They are either a boost or a buck converter and cannot be a buck-boost converter. That is, their obtainable output voltage range is limited to either greater or smaller than the input voltage.

- Their main circuits cannot be interchangeable. In other words, neither the $\mathrm{V}$-source converter main circuit can be used for the I-source converter, nor vice versa.

- They are vulnerable to EMI noise in terms of reliability.

The $\mathrm{Z}$ Source Converter overcomes all the limitations of the traditional $\mathrm{V}$ and I source converters. Z source has buckboost operation, higher noise immunity, no damage due to shoot through and can operate both in $\mathrm{V}$ and/or I source modes.

\section{Efficiency vs Duty ratio}

The Fig. 4 shows graph of efficiency vs duty ratio. The efficiency [4] of Z-source converter is sensitive to duty ratio at which it is operated. It can be seen from the graph that the efficiency sharply decreases when the converter is operated at duty ratios beyond 0.3 .

So, it is very much necessary to operate the converter at lower range of duty ratio to get higher efficiency.

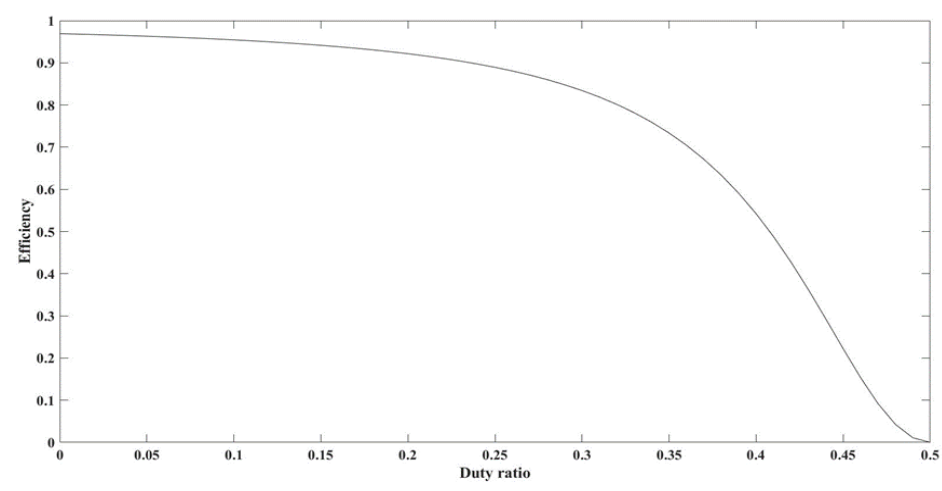

Fig. 4. Efficiency vs Duty ratio

\section{Z-SOURCE VS BUCK BOOST CONVERTER}

A comparison between Z-Source and buck-boost converter is made, in which efficiency, output voltage ripple and output current ripple is compared using a Simulink model.

The model is constructed for parameters given in Table I. The values of inductors and capacitors for both Z-Source and Buck-boost converter are calculated and are given in Table II.

TABLE I. PARAMETERS FOR CONVERTERS

\begin{tabular}{|c|c|}
\hline Parameters & Values \\
\hline Vin & $50 \mathrm{~V}$ \\
\hline Vout & $55 \mathrm{~V}$ \\
\hline Max. Output Power & $1650 \mathrm{~W}$ \\
\hline Voltage ripple & $1 \%$ \\
\hline Inductor current ripple & $20 \%$ \\
\hline Frequency & $10 \mathrm{kHz}$ \\
\hline
\end{tabular}

TABLE II. CALCULATED VALUES

\begin{tabular}{|c|c|c|}
\hline Parameters & $\begin{array}{c}\text { Z-Source } \\
\text { Converter }\end{array}$ & $\begin{array}{c}\text { Buck-Boost } \\
\text { Converter }\end{array}$ \\
\hline Duty ratio & 0.12 & 0.56 \\
\hline Inductance & $109.8 \mathrm{uH}$ & $177.4 \mathrm{uH}$ \\
\hline Capacitance & $150 \mathrm{uF}$ & $3.3 \mathrm{mF}$ \\
\hline Load & $1.833 \Omega$ & $1.833 \Omega$ \\
\hline
\end{tabular}

\section{MATLAB circuit}

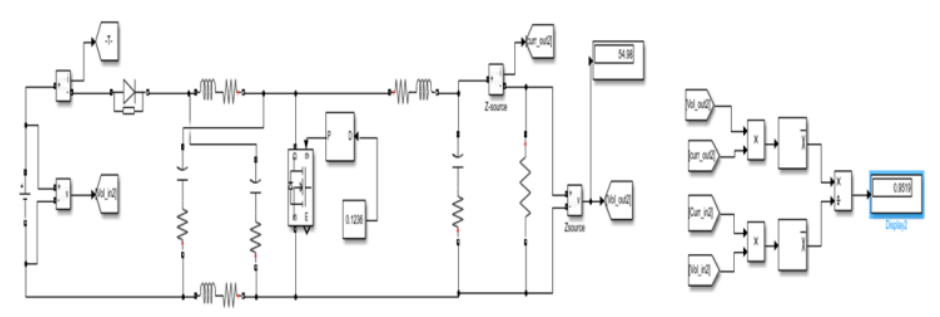

Fig. 5. Z-source Converter 

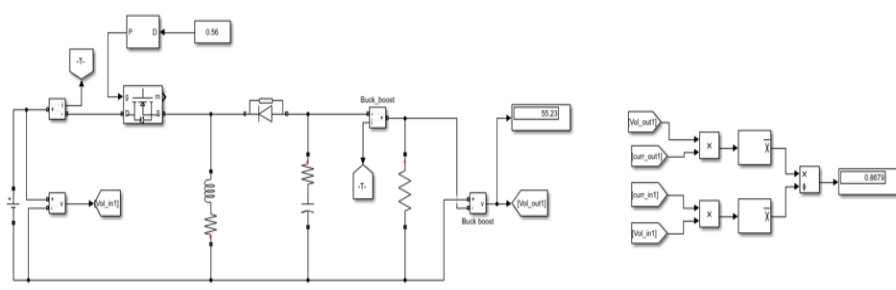

Fig. 6. Buck-Boost Converter

\section{E. Comparison}

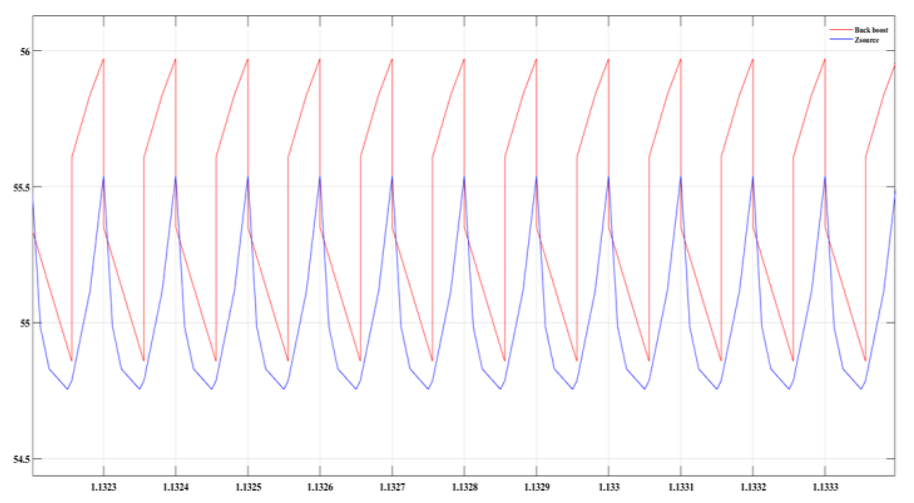

Fig. 7. Voltage ripple vs Time

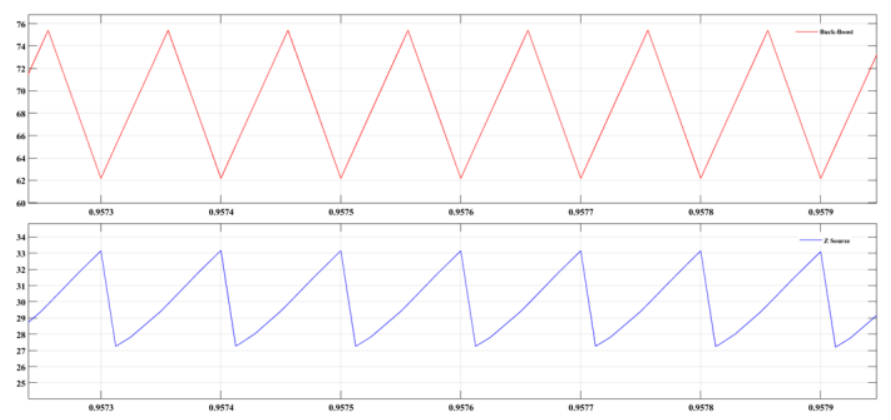

Fig. 8. Current ripple vs Time

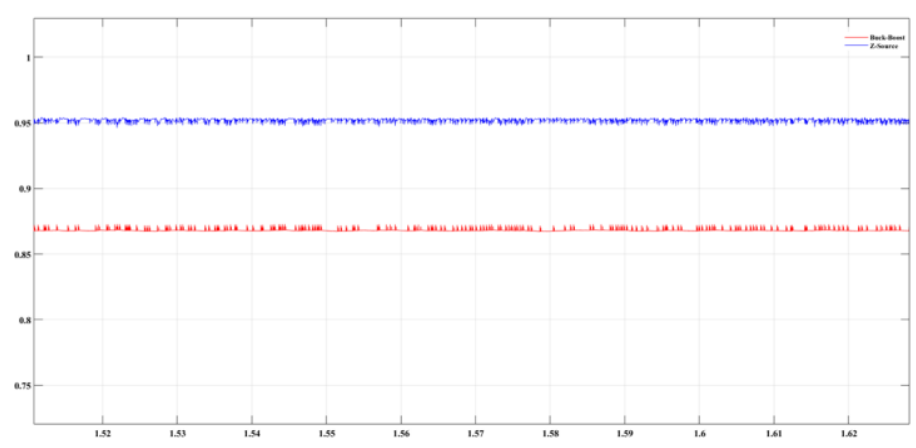

Fig. 9. Efficiency vs Time

From the comparison of voltage ripple (Fig.7), current ripple (Fig.8) and efficiency (Fig.9) it can be inferred that
Z-source converter (blue color waveform) provides greater efficiency, 95\% and uses smaller value of inductances and capacitances for same ripple compared to buck-boost converter (red color waveform) which provides $86 \%$ efficiency. Hence, Z-source is a better choice for charging circuit.

\section{BATTERY CHARGING MODE}

The performance and life of the battery is affected by the charging method being employed for charging the battery. With high charging currents, the battery operates with reduced chemical reactions which in turn increase the internal resistance of the battery. With this increase in resistance the battery temperature increases sharply and can cause significant damage to the battery. On the other hand, with very low charging currents, the time taken to charge is very long and hence not practical. Therefore, the charging method is important in order to exert efficient performance of the battery within a stipulated time period.

TABLE III. BATTERY SPECIFICATIONS

\begin{tabular}{|c|c|}
\hline Parameters & Values \\
\hline Type & Li-ion \\
\hline Nominal Voltage & $48 \mathrm{~V}$ \\
\hline Rated capacity & $60 \mathrm{Ah}$ \\
\hline Fully charged voltage & $55.87 \mathrm{~V}$ \\
\hline Cut-off Voltage & $36 \mathrm{~V}$ \\
\hline Internal Resistance & $0.0096 \mathrm{ohms}$ \\
\hline
\end{tabular}

\section{F. Constant current mode [CC]}

As the name suggests, the $\mathrm{CC}$ mode charges the battery by supplying constant current while the battery voltage will vary. When the battery is fully charged the current should be reduced to a trickle to avoid damages due to overheating. Compared to the $\mathrm{CV}$ mode of charging, the $\mathrm{CC}$ mode is quicker but requires greater attention during the final stages of charging to avoid overcharging.[1]

\section{$G$. Constant voltage mode [CV]}

As the name suggests, the CV mode charges the battery with a constant voltage while the current will vary. Compared to $\mathrm{CC}$ mode the $\mathrm{CV}$ mode has relatively simpler circuit structure and control design. Unlike in CC mode, in $\mathrm{CV}$ mode the current decreases as the battery is fully charged. The charger automatically enters the float charging mode, when the battery is fully charged. In initial stages of charging, the charging current is very large on account of very low battery terminal voltage. This can cause temperature to increase and damage the battery plates and the overall life of the battery. In order to overcome this problem, a multistage voltage charging method can be implemented. Where the battery is charged at lower voltages in the initial stages and as the battery terminal voltage increases, the battery can be charged at a higher voltage.[1] 


\section{H. Implementation}

The battery is initially charged at CC mode. This method is continued till the measured voltage across battery is equal to the rated nominal value. The charging method is then switched to $\mathrm{CV}$ mode in which the voltage is kept constant and the amount of current into the battery is reduced. This continues till the battery is completely charged.

The shift in charging mode from $\mathrm{CC}$ mode to $\mathrm{CV}$ mode is decided based on the state of charge [SOC] of the battery. The SOC of the battery is taken as a feedback and is given as an input to a MATLAB function block.

In this model the shift from $\mathrm{CC}$ mode to $\mathrm{CV}$ mode is done at SOC of $95 \%$.

\section{ClOSED LOOP CONTROL OF Z-SOURCE CONVERTER}

To obtain the constant values of current and voltage in $\mathrm{CC}$ and CV modes respectively, a feedback control mechanism is used. A code is written in the MATLAB function block which acts as feedback control for both $\mathrm{CC}$ and $\mathrm{CV}$ modes of charging. Fig.11 shows the MATLAB function block. This function block takes voltage error signal, current error signal and SOC as the input and gives out duty ratio responsible for PWM as output.

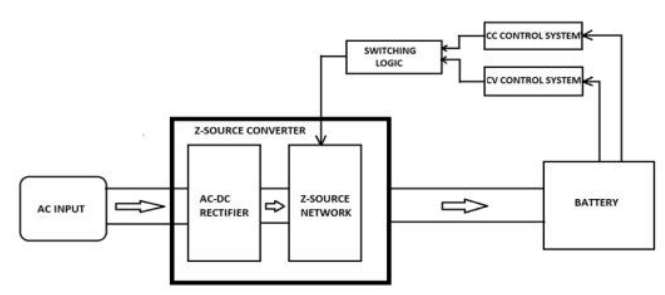

Fig. 10. Block diagram of the charger

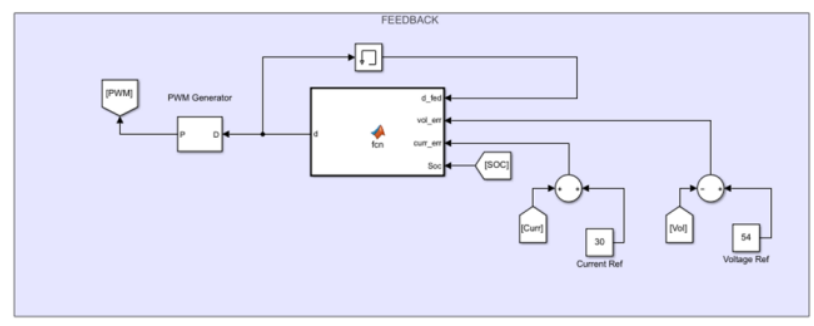

Fig. 11. MATLAB Function block

\section{RESUlTS AND DISCUSSION}

For the required application of battery charging, we take DC output voltage or load voltage as $55 \mathrm{~V}$ and DC input voltage as $50 \mathrm{~V}$. The switching frequency of switch $\mathrm{S}$ is $10 \mathrm{kHz}$ and load resistance is taken as $1.833 \Omega$. The current ripple is taken to be $20 \%$ and voltage ripple $1 \%$. Using equation (8) $\mathrm{d}=0.12$, using equation (14) $\mathrm{L}=109.98 \mathrm{uH}$ and using equation (20) $\mathrm{C}=136.38 \mathrm{uF}$.

\section{MATLAB circuit}

The battery charger takes $50 \mathrm{Vpeak}, 50 \mathrm{~Hz} \mathrm{AC}$ as input. This is converted into pulsating DC using a bridge rectifier. This is appropriately boosted to the required value using $\mathrm{Z}$ source. The output of the Z-source is connected to the battery for charging operation.

A feedback control mechanism controls $\mathrm{CC}$ and $\mathrm{CV}$ modes. The values of inductors and capacitors used are $200 \mathrm{uH}$ and $150 \mathrm{uF}$ respectively. The value of filter inductor used is $20 \mathrm{mH}$. For more practical results, resistive losses and switching losses are considered. The resistance of inductor, capacitor and switch are chosen to be $0.005 \mathrm{ohms}, 0.1 \mathrm{ohms}$ and $0.077 \mathrm{ohms}$ respectively. The forward voltage of diode is chosen to be 0.7V. The MATLAB circuit is as shown in the Fig. 12.

\section{J. Waveforms}

The circuit is simulated for a 1000 simulation time units. The initial SOC of the battery is chosen to be $90 \%$ in order to get the results at both $\mathrm{CC}$ and $\mathrm{CV}$ mode of operation of the charger.

The Fig. 13 shows the waveform of SOC vs time. It can be seen that the rise in SOC is linear in CC mode and the slope goes on decreasing in CV mode.

The Fig.14 shows the waveform of Current vs Time and Fig. 15 shows the waveform of Voltage vs time. The current is held constant and the voltage sees a rise in $\mathrm{CC}$ mode and voltage is held constant and the current sees a fall in $\mathrm{CV}$ mode respectively.

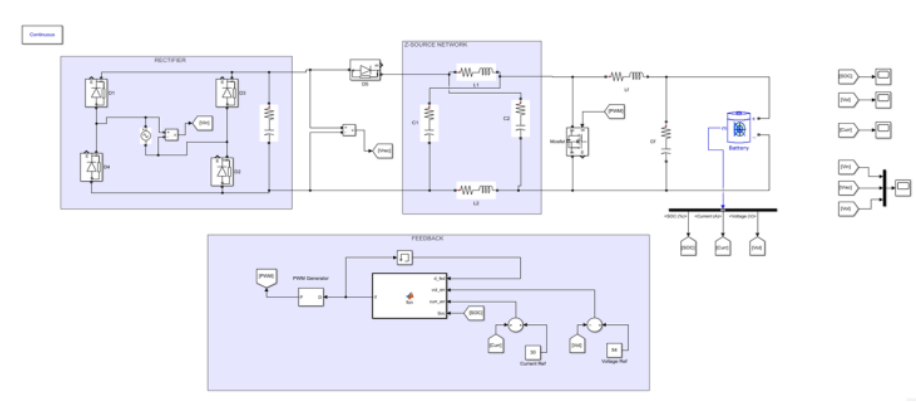

Fig. 12. MATLAB circuit

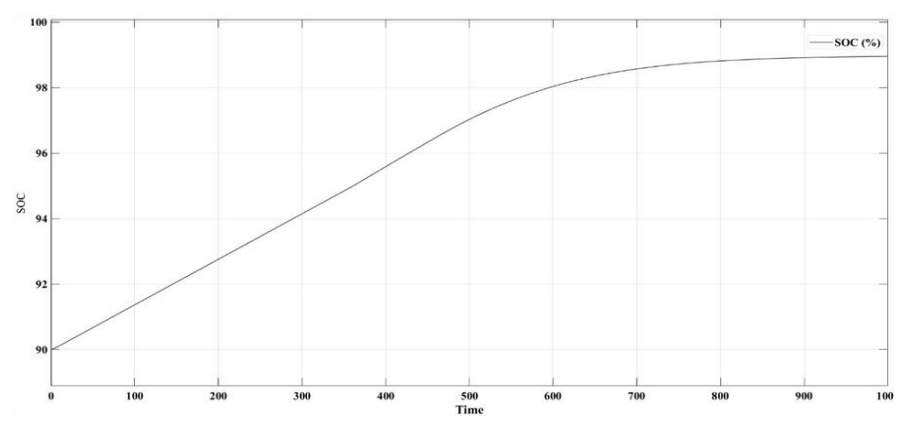

Fig. 13. SOC vs Time 


\section{International Journal of Engineering Applied Sciences and Technology, 2020 \\ Vol. 5, Issue 4, ISSN No. 2455-2143, Pages 348-354 \\ Published Online August 2020 in IJEAST (http://www.ijeast.com)}

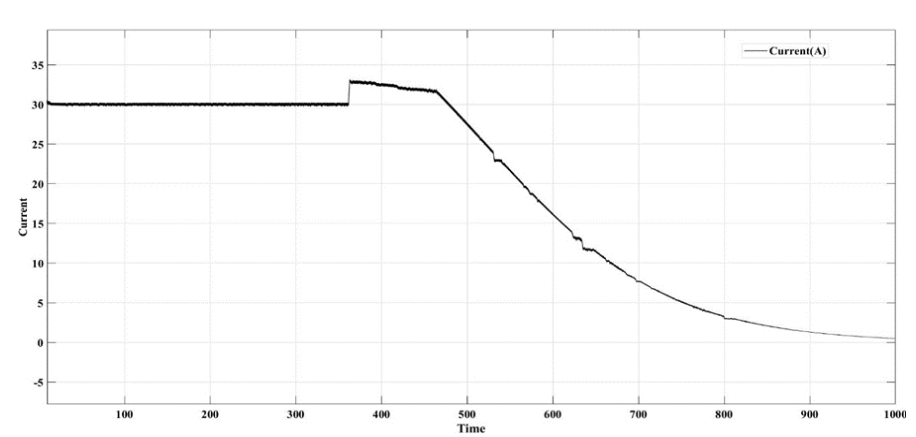

Fig.14. Current vs Time

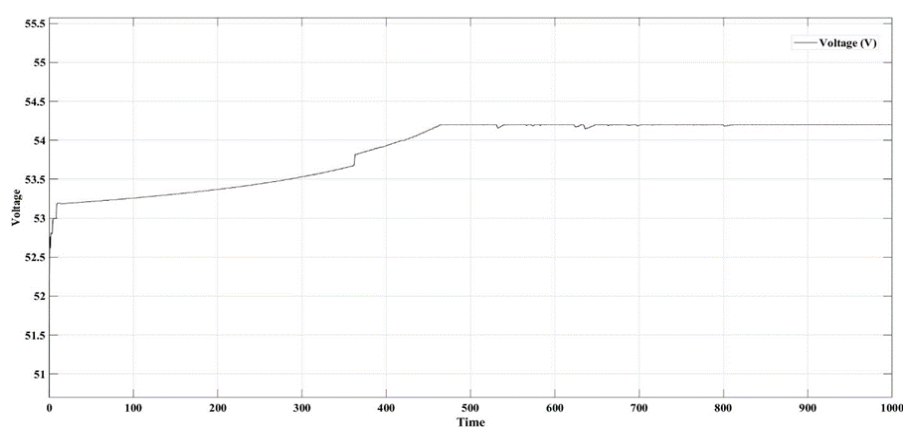

Fig. 15. Voltage vs Time

\section{CONCLUSION}

The paper presented a method of implementing Z-Source Converter (ZSC) to charge the vehicle battery from the grid using AC-DC power conversion with constant current (CC) and constant voltage (CV) charging modes. The theoretical design for charging modes between threshold values was done and the circuit was simulated and verified. The MATLAB simulation of the charger consisting of Z-source topology has desirable performance. The feedback mechanism included in the charger circuit acts as a good control for both CC and CV modes by controlling the duty ratio below 0.3 . It was inferred from the design comparison and simulation that the Z-source converter provides greater efficiency, of about $95 \%$ and uses smaller value of inductances and capacitances for same ripple compared to buck-boost converter.

\section{ACKNOWLEDGMENT}

The authors gratefully acknowledge Dr. Ravishankar B V, Principal, B.M.S.C.E. and Dr. P Meena, HOD, Department of Electrical and Electronics Engineering, B.M.S.C.E. for their constant support during the course of this work.

\section{REFERENCES}

[1] Sandy J. Thomson ; Polly Thomas ; Anjali R. ; Elizabeth Rajan, (2018), "Design and Prototype Modelling of a CC/CV Electric Vehicle Battery Charging Circuit," International Conference on Circuits and Systems in Digital Enterprise Technology (ICCSDET), Kottayam, India, (pp. 1-5), DOI: 10.1109/ICCSDET.2018.8821071.
[2] Zhu. X and Zhang .B, (July 2017), "High step-up quasi-Zsource DC-DC converters with single switched capacitor branch," in Journal of Modern Power Systems and Clean Energy, vol. 5, no. 4, (pp. 537-547), DOI: 10.1007/s40565-017-0304-1.

[3] Zeng. J, Wu. J, Yu. Z and Liu. J, (2017), "Switched Zsource DC-DC converter", IECON 2017 - 43rd Annual Conference of the IEEE Industrial Electronics Society, Beijing,(pp. 8039-8044), DOI: 109/IECON.2017.8217410.

[4] Galigekere.V.P and Kazimierczuk.M.K, (April 2012) "Analysis of PWM Z-Source DC-DC Converter in CCM for Steady State," in IEEE Transactions on Circuits and Systems I: Regular Papers, vol. 59, no. 4, (pp. 854-863), DOI: 10.1109/TCSI.2011.2169742.

[5] Galigekere V. P and Kazimierczuk M.K, (May 2011) "Small-signal modeling of PWM Z-source converter by circuit-averaging technique", IEEE International Symposium on Circuits and Systems (ISCAS), (pp. 16001603).

[6] Musavi. F, Eberle. W and Dunford W.G, (July-Aug. 2011) "A High-Performance Single-Phase Bridgeless Interleaved PFC Converter for Plug-in Hybrid Electric Vehicle Battery Chargers," in IEEE Transactions on Industry Applications, vol.47,no.4,(pp.1833-1843), DOI:10.1109/TIA.2011.2156753.

[7] M. Shen and F. Z. Peng, (Jan 2008) "Operation modes and characteristics of the Z-source inverter with small inductance or low power factor", IEEE Trans. Ind. Electron., vol. 55, no. 1, (pp. 89-96).

[8] Liu. J, Hu. J and Xu. L, (Sep 2007)"Dynamic modeling and analysis of Z-source converter-derivation of ac small signal model and design-oriented analysis", IEEE Trans. Power. Electron., vol. 22, no. 5, (pp. 1786-1796).

[9] P. C. Loh, D. M. Vilathgamuwa, C. J. Gajanayake, Y. R. Lim and C. W. Teo, (Mar. 2007) "Transient modeling and analysis of pulse-width modulated Z-source inverter", IEEE Trans. Power. Electron., vol. 22, no. 2, (pp. 498-507).

[10] R. J. Wai, C. Y. Lin, R. Y. Duan and Y. R. Chang, (Jan. 2007) "High-efficiency dc-dc converter with high voltage gain and reduced switch stress", IEEE Trans. Ind. Electron., vol. 54, no. 1, (pp. 354-364).

[11] Peng F. Z, "Z-source inverter", (Mar. 2003), IEEE Trans. Ind. Appl., vol. 39, no. 2, (pp. 504-510). 
International Journal of Engineering Applied Sciences and Technology, 2020

Vol. 5, Issue 4, ISSN No. 2455-2143, Pages 348-354

Published Online August 2020 in IJEAST (http://www.ijeast.com)

[12] R. D. Middlebrook and S. Cuk, (1976) "A general unified approach to modelling switching-converter power stages", IEEE Power Electronics Specialists Conference PESC', (pp. 18-34). 